\title{
Article \\ Factors Influencing Continued Usage Behavior on Mobile Health Applications
}

\author{
Pei Wu ${ }^{1}$, Runtong Zhang ${ }^{1, * \mathbb{C}}$, Xiaomin Zhu ${ }^{2}$ and Manlu Liu ${ }^{3}$ \\ 1 School of Economics and Management, Beijing Jiaotong University, Beijing 100044, China; \\ peiwwu@bjtu.edu.cn \\ 2 School of Mechanical, Electronic and Control Engineering, Beijing Jiaotong University, Beijing 100044, China; \\ xmzhu@bjtu.edu.cn \\ 3 Rochester Institute of Technology, Saunders College of Business, Rochester, NY 14623, USA; \\ manluliu@saunders.rit.edu \\ * Correspondence: rtzhang@bjtu.edu.cn; Tel.: +86-138-0139-9206
}

Citation: Wu, P.; Zhang, R.; Zhu, X.; Liu, M. Factors Influencing

Continued Usage Behavior on Mobile Health Applications. Healthcare 2022, 10, 208. https://doi.org/10.3390/ healthcare10020208

Academic Editor: Daniele Giansanti

Received: 13 December 2021

Accepted: 19 January 2022

Published: 21 January 2022

Publisher's Note: MDPI stays neutral with regard to jurisdictional claims in published maps and institutional affiliations.

Copyright: (C) 2022 by the authors. Licensee MDPI, Basel, Switzerland. This article is an open access article distributed under the terms and conditions of the Creative Commons Attribution (CC BY) license (https:// creativecommons.org/licenses/by/ $4.0 /)$.

\begin{abstract}
Background: As people pay more attention to health, mobile health applications (mHealth apps) are becoming popular. These apps offer health services that run on mobile devices to help improve users' health behaviors. However, few studies explore what motivates users to continue to use these apps. This study proposes antecedents influencing users' electronic satisfaction (e-satisfaction) and their continued behaviors of using mHealth apps. Based on the extended Unified Theory of Acceptance and Use of Technology (UTAUT2), this study constructs a research model including perceived reliability and online review to predict the continued usage behavior on mHealth apps in China; (2) Methods: We conduct an online survey to collect data from participants who have used mHealth apps. This study receives 327 valid responses and tests the research model using the partial least squares structural equation model approach; (3) Results: Our results find that antecedents positively affect continued usage intention through the mediation role of e-satisfaction with mHealth apps. Interestingly, this study reveals that habit positively affects the continued usage behavior and moderates the effect of e-satisfaction and continued intention of using mHealth apps; (4) Conclusions: This study presents theoretical implications on the extended UTAUT2 and provides practical implications understanding of managing mHealth apps in China.
\end{abstract}

Keywords: mHealth apps; e-satisfaction; continued usage intention; continued usage behavior; UTAUT2

\section{Introduction}

The speedy evolutions of information technology (IT) have encouraged mobile devices to become a broad part of daily life. The widespread mobile device usage contributes to the integration of health and mobile services [1]. mHealth apps have changed the way health information acquiring and improved the efficacy of services in the healthcare field $[2,3]$. Zion Market Research [4] proposes that the mHealth apps market will be more than USD 111 billion by 2025 . However, people use mHealth apps unfrequently, likely because these apps are perceived as unreliable [5]. The development of mHealth apps depends on their attracting and retaining users. Understanding users' continued usage behavior is essential for the success of mHealth apps. In this study, mHealth apps refer to applications installed on mobile devices that provide users with health information and have simple reminders and health data tracking functions to effectively promote users' self-health behaviors and improve the efficiency of health services and the accessibility of health information.

Though mHealth apps thrive, people rarely continue to use such apps after the initial acceptance [5]. Among the empirical studies on users' continued use of health technology, researchers have explored the impact of factors on the continued behavior of using health apps. For example, Cho [6] identified the effects of perceptual and emotional factors on motivating continuous using health apps relying on the post-acceptance model and 
the technology acceptance model; based on the social cognitive theory, Kim and Han [7] examined the effects of health technology self-efficacy, self-evaluative outcome expectations, self-regulation, and privacy risk on older users' continued intention to use health apps. Recently, one previous study proposed a research model including context and contents values to explore the intention of users over the age of 40 in using health apps on mobile phones [8], another study applied the expectation-confirmation model and the investment model to explore the effects of perceived usefulness, satisfaction, and commitment on continuance intention to use health apps [9]. However, few studies explored the effects of factors on the intention and behavior of keeping to use mHealth apps based on the extended UTAUT2.

In addition, previous studies have conducted and proposed key factors affecting users' adoption intentions in using mHealth, such as performance expectancy, effort expectancy, social influence, and facilitating conditions [10,11]; self-efficacy and response-efficacy [12]. However, rarely studies explore the mediation role of user e-satisfaction among antecedents and continued intention of using mHealth apps. E-satisfaction refers to users' satisfaction with the experience on mHealth apps. If the effects of using mHealth apps meet and exceed users' expectations, users may be satisfied with mHealth apps and willing to have a continued usage intention. Furthermore, although user's habit is a critical factor in affecting continued intention and behavior when using mobile food ordering apps [13], few studies discuss the moderation role of habit in mHealth apps continues to use. To address the above research gaps, this study focuses on the following research questions:

$R Q$ 1: Which factors influence intention to continue to use mHealth apps?

RQ 2: How do various factors influence the continued usage of mHealth apps?

The research objective of this paper is to explore the factors that affect the users' intentions to keep using mHealth apps, and their continued behaviors that are affected by the intentions. First, based on the extended UTAUT2, this study identifies the determinants of intention to continue to use mHealth apps through the mediation role of e-satisfaction. Second, this study attempts to explore the impacts of the habit of using mobile apps on the continued usage behavior and innovatively analyzed the moderating effect of habits on the relationship between e-satisfaction and continued usage intention. Third, this study examines the effects of antecedents on users' e-satisfaction with mHealth apps through integrating the perceived reliability and online review in the extended UTAUT2.

The contributions of this study include three aspects. First, through exploring the effects of antecedents on users' e-satisfaction with mHealth apps, this study makes an original contribution to integrating e-satisfaction into the UTAUT2 in the context of mHealth apps. Users' e-satisfaction, as a positive attitude, has significant effects on the continued intention of using mHealth, which promotes the success of mHealth apps. Second, the characterization of e-satisfaction is important for our increased understanding of the effects of antecedents on continued usage intentions. This study identifies the mediation role of e-satisfaction on the relationships between antecedents and continued usage intentions. Third, the empirical work presents here provides one of the first investigations into how habits influence the relationship between e-satisfaction and continued usage intentions. The results of this study make a major contribution to research on the continued behavior of using mHealth apps by demonstrating the moderating effect of the habit of using mHealth apps on the positive association between e-satisfaction and continued usage intentions.

The rest of the paper is shown as follows. First, this study presents the literature review. Second, based on the UTAUT2, this study provides the hypotheses and research model. Third, we describe our research methods including four sections (development of the questionnaire, data collection, and data analysis). Fourth, we introduce our results from four aspects including measurement model analysis and structural model analysis. Finally, we discuss the theoretical implications, practical implications, and limitations of this study. 


\section{Literature Review}

The popularity of mobile devices has promoted the development of various apps that provide people with a wide range of services [14,15]. Considering that people are paying more attention to health, mHealth apps have developed into an important tool for users to solve health problems [16,17]. Currently, in developing countries, mHealth apps can offer faster ways to share information related to patients' diseases and provide a wealth of professional health information $[18,19]$. Based on the analysis of functions that support health behavior change techniques, tracking health data is the most important feature in mHealth apps [20]. Setting customized goals, notifications and reminders, and access to health information are the second most important features for users [20]. In addition, mobile technologies provide users with adaptive, low-cost, and easily accessible self-management interventions [21-23].

People most often learn of mHealth apps from relatives or friends rather than from health professionals and existing studies have found that social influence positively affects behavioral intention to use mHealth [12]. Previous studies have found that people who use mHealth apps continuously for a long time can effectively improve their overall health fitness $[7,20]$. Though the commitment to mHealth apps is beneficial, the abandoning phenomenon of such apps is common [20]. People initially downloaded mHealth apps but later uninstalled them [9]. The reason for this phenomenon may be that users who are not positively affected by using mHealth apps have no beliefs in performance expectancy, social influence, facilitating condition and perceived reliability of these apps [12,24].

Previous studies discussed the effects of different factors on the continued use of mobile apps, such as perceived usefulness, satisfaction, and commitment [6,9]; price value, habit, online review, and e-satisfaction [13]. In the context of mHealth, the existing evidence from the effects of performance expectancy and effort expectancy on users' behaviors of using mHealth services are inconsistent. For example, Mohammad et al. [12] found that effort expectancy did not affect behavioral intention and perceived reliability of services quality significantly affects individuals' intentions to accept mHealth services; Hoque and Sorwar [25] found that effort expectancy significantly affects users' behavioral intention. In addition, satisfaction with mobile apps and attitude toward such apps has proved to be a critical factor of influencing the continued intention and behavior of using these apps $[13,26,27]$. For example, one study found that satisfaction has mediation effects on the key factors (perceived usefulness, perceived ease of use, flow experience, and behavioral change techniques) of continued intention to use mHealth apps [26]; another study revealed that attitude positively influences intention to use mHealth apps from protection motivation and network externality perspectives [27].

\section{Theoretical Background and Hypotheses Development}

UTAUT is developed by integrating eight user acceptance models that include the technology acceptance model (TAM), reasoned action theory, motivational model, planned behavior theory, the model combining the TAM and planned behavior theory, personal computer utilization model, innovation diffusion theory, and social cognitive theory [28]. Based on UTAUT, previous studies have assessed people's acceptance of emerging technology in developing countries [29]. For example, an empirical study has explored the intention of the elderly to use emerging health apps [30]. Some researchers have focused on the intention of using mobile technology [31,32]. Venkatesh et al. [33] extended hedonic motivation, price value, and habit in UTAUT affecting individuals' acceptance of information technology and found that UTAUT2, compared with UTAUT, increased the interpretation of individuals' usage intention and behavior. Based on UTAUT2, previous studies have examined the continued intention of mobile technology. For example, Alalwan [13] investigated the positive effects of online review, performance expectancy, hedonic motivation, and price value on e-satisfaction and continued intention of using mobile food order apps; Beh et al. [34] explored the determinants of smartwatches usage and provided useful insights into drivers of the emerging technology for fitness and health monitoring. 
UTAUT is regarded as a theoretical framework to study the continued usage behavior of mHealth apps and proposes antecedent factors that influence users' intentions for keeping to use mHealth apps. Compared with UTAUT, UTAUT2 greatly improves the interpretation of individuals' usage behavior and is developed to illuminate users' continued usage behavior of mHealth apps $[33,35]$. Price value is important as people must bear the costs related to purchasing mobile devices and mHealth services [33]. Habit in technology use is a significant factor in predicting technology acceptance [33]. Online reviews have drawn widespread attention in mobile technology literature as review visibility is quite significant and meaningful in the consumption process [36]. Perceived reliability is the potential determinant of users' willingness to adopt mHealth service innovations [12,37]. However, few studies focus on the effects of perceived reliability and online review on the continued intention of using mHealth apps and the mediating role of e-satisfaction in the theoretical framework of UTAUT2.

To understand the theoretical framework, this study proposes a research model (see Figure 1) to address the research questions associated with the continued usage behavior of mHealth apps. This study integrates online review and perceived reliability into UTAUT2 to tailor it to the research of individuals' continued acceptance of mHealth apps. This study focuses on the UTAUT2 to explore the effects of antecedents on users' e-satisfaction with mHealth apps and the mediation role of e-satisfaction on the relationship between antecedents and continued intention. In addition, this study explores the moderation role of habit on the relationship between e-satisfaction and continued usage intentions.

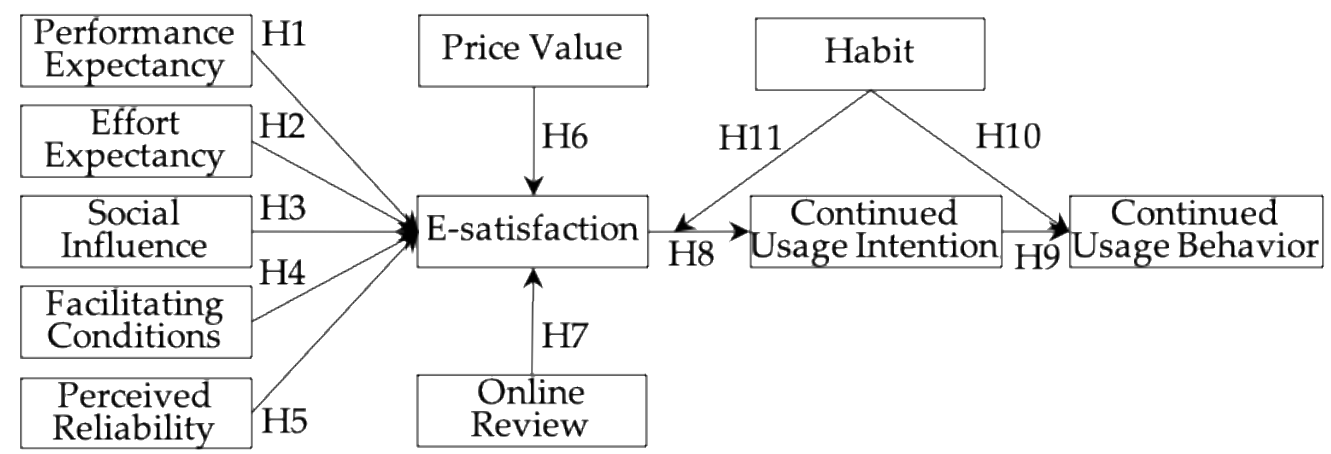

Figure 1. Research model.

\subsection{Performance Expectance}

Emerging technologies usage can provide individuals with benefits in conducting certain activities, which is the definition of performance expectancy [33]. People will be more willing to adopt emerging technologies if they believe that technologies have advantages [38]. When people use mHealth services, performance expectancy represents their expectations in the case of demand environments [12] and is the main driver of their satisfaction with the environments. Moreover, mHealth apps are the application of mobile technologies in healthcare and provide convenience for the communication among users due to the characteristics, such as mobility and flexibility. People using mHealth apps can acquire comprehensive health information and consult professional physicians at any time and any place [39]. People can choose professional physicians for health consultation without location movement through these apps. Using mHealth apps is particularly convenient in consideration of issues such as queuing for registration, transportation costs, and long waiting times for health consultations. In other words, if users have high utilitarian value when using such innovative mHealth apps, they may be satisfied [13].

Hypothesis 1 (H1). Performance expectancy positively affects users' e-satisfaction with mHealth apps. 


\subsection{Effort Expectance}

Effort expectancy explains the ease of usage behavior of technologies, which is one of the significant components in researches on technologies acceptance [33,40]. Effort expectancy is closely related to users' satisfaction $[13,41]$ and has an effect on satisfaction in the field of online learning $[13,42]$. In the context of mHealth apps, people complete the evaluation of health information without any assistance from healthcare staff. People spend time and effort to reflect the complexity and ease of using mHealth apps. Peoples' satisfaction with mHealth apps can be determined by the ease and simplicity of using them.

Hypothesis 2 (H2). Effort expectancy positively affects users' e-satisfaction with mHealth apps.

\subsection{Social Influence}

The definition of social influence is the extent to which people are influenced by essential others (family and friends) who recommend using emerging technologies [33]. Social influence is one of the most significant factors related to individuals' usage and rejection of mHealth apps. Most people are not completely familiar with mHealth apps and are mainly influenced by others' opinions and attitudes, such as those of friends, relatives, and colleagues $[13,35,43]$. Moreover, when judging users' satisfaction with mHealth apps, it is important to point out that they are susceptible to the effect of other users. People may also gain social recognition from others, which will increase their social value and their satisfaction with mHealth apps [44]. In addition, social influence significantly impacts users' satisfaction with mobile apps [45].

Hypothesis 3 (H3). Social influence positively affects users' e-satisfaction with mHealth apps.

\subsection{Facilitating Conditions}

Facilitating conditions refer to peoples' perceptions of the technological infrastructures to support using emerging technologies [28]. Facilitating conditions positively affect peoples' intention of using smartphones for health services [46]. Peoples' experience in mHealth apps and the degree of satisfaction depend on the technical infrastructure and human support available at their request [13]. The role of personnel support in services is essential to ensure the delivery of high-quality services. Considering the important role of convenience, if users obtain a sufficient level of technology, organization, infrastructure, and personnel support when using mHealth apps, they may have simpler and more convenient experiences, thereby making them more satisfied with such apps [13]. Moreover, prior studies have proved that close relationships exist between facilitating conditions and satisfaction in healthcare $[47,48]$.

Hypothesis 4 (H4). Facilitating conditions positively affect users' e-satisfaction with mHealth apps.

\subsection{Perceived Reliability}

Perceived reliability refers to the extent to which people believe emerging technologies work consistently and accurately [37]. People who decide to adopt services based on emerging technology usually regard perceived reliability as a crucial factor [37]. Perceived reliability is critical to whether users decide to adopt mHealth apps. For example, if people believe that mHealth apps are reliable and may cause benefits, they will be willing to continue using them. Barua et al. [49] shed light on the effect of perceived reliability on users' satisfaction with self-services technologies. Moreover, perceived reliability positively affects users' satisfaction with mobile banking [50]. People are satisfied when they find that emerging technologies are reliable and safe [49,51,52].

Hypothesis 5 (H5). Perceived reliability positively affects users' e-satisfaction with mHealth apps. 


\subsection{Price Value}

The definition of price value is peoples' perceived trade-off between their profit and cost in using IT [33]. When the perceived benefits of usage behavior exceed the monetary costs, price value will increase users' satisfaction with mHealth apps. Using mHealth apps reduces the financial and non-financial costs of going to hospitals. For example, if physicians can provide health services through mHealth apps, the patient does not need to go to the hospital for services. This saves the patients and physicians financial costs and valuable time. People may be satisfied with the experience of using mHealth apps if relevant benefits are considered higher than financial costs.

Hypothesis 6 (H6). Price value positively affects users' e-satisfaction with mHealth apps.

\subsection{Online Review}

Online reviews are word-of-mouth information on virtual platforms and are popular all over the world [53]. People are willing to read online reviews that have an influence on their consumption decisions $[53,54]$. The interactivity of mHealth apps allows users to create online reviews, feedback on health services, and attitudes on mHealth apps [55]. A significant correlation exists between online reviews and users' willingness to use experience, such as entertainment and ease of use [56]. If users consider online reviews as valuable, useful, comprehensive, credible, and updated, they may be satisfied with mHealth apps [13].

Hypothesis 7 (H7). Online review positively affects users' e-satisfaction with mHealth apps.

\subsection{E-Satisfaction}

E-satisfaction refers to how satisfied people are with their experience with an electronic commerce company [57]. Satisfaction reflects the degree to which users derive a positive attitude from a service experience $[49,58]$. E-satisfaction has an effect on the specific transaction based on the immediate usage experience, which may positively impact the continued intention of technologies adoption $[59,60]$. If the effects of using mHealth apps meet and exceed users' expectations, they may be satisfied with mHealth apps and they might be more likely to intend to continue to use it. Users who are satisfied with mHealth apps may be motivated to continue using such apps. E-satisfaction stems from the difference between users' expectations and the actual benefits of specific tools, and higher satisfaction may enhance people's tendency to reuse these tools $[59,61]$.

Hypothesis 8 (H8). E-satisfaction positively affects users' continued usage intention.

\subsection{Continued Usage Intention}

Continued usage intentions refer to the degree of users' perception of the willingness of continued usage behaviors [12,62]. In various fields, behaviors have been proven to be best predicted by behavioral intention [63]. Usage intentions and behaviors exist significant correlations, and continued usage behavior has been proved to be considerably affected by individuals' intentions in the field of IT $[62,64]$. In addition, the usage intention positively affects the behavior of using mobile services in the healthcare field [12,60,65]. Continued usage intention predicted the behavior of using IT [66]. In the context of healthcare, users' intention to keep using mHealth apps may predict the behavior of using these apps.

Hypothesis 9 (H9). Continued usage intention positively affects the behavior of using mHealth apps.

\subsection{Habit}

Habit refers to the extent to which people tend to carry out something automatically after a period of experience and reflects the result of previous usage experience [33,67]. Habit can be expressed as the tendency of users to act spontaneously because of their accumulated 
learning experience [67]. Habit reflects stable behaviors without active consideration and is repeatedly performed when the behaviors occur. When frequent behaviors are repeated to become habits, these behaviors are guided by automated cognitive processes rather than elaborate decision processing based on satisfaction and continued intentions [68]. In the context of healthcare, habit in mHealth apps use may predict the continued behavior of using these apps.

\section{Hypothesis 10 (H10). Habit positively affects continued behavior of using mHealth apps.}

Habit can be a basis for understanding the interaction between users and IT [33]. Habit refers to the tendency of users to take actions based on past experience [67]. Consumers' habit in using mHealth apps for more pragmatic purposes rather than the novelty. Habit may impact users' attitudes and beliefs that determine users' intention of using mHealth apps and is one of the significant factors for mobile app acceptance [69-71]. The positive effect between e-satisfaction and continued intention may be affected by habits in mHealth apps use.

Hypothesis 11 (H11). Habit positively moderates the effects of e-satisfaction on the continued intention of using mHealth apps.

\section{Methods}

\subsection{Development of Questionnaire}

To guarantee the questionnaire validity and reliability, this study adapted items from previously validated instruments to use with the context of mHealth apps in China. We adopted the items from Venkatesh et al. [28,33] to measure performance expectancy, effort expectancy, social influence, and facilitating conditions. We used the items from Venkatesh et al. [33] and Alalwan [13] to examine price value, habit, and continued intention. We adapted the items from Alalwan [13] to measure online review and e-satisfaction. We adopted the measurement instruments from Mohammad et al. [12] to measure perceived reliability and continued usage behavior. We used a Likert seven-point scale to take the measurements of all items, which were listed in Appendix A.

Before an online survey, ambiguous items were checked through two stages: the expert review and the pilot study. In the first stage, five experts were invited to verify the measurement instruments whether fit the context of mHealth apps and review the instruments to see if they accurately reflected the construction of UTAUT2. All experts confirmed that the writing style and the feasibility of the measurement instruments of constructs have fit the context of mHealth apps and are accurate. In the second stage, we invited 20 interviewees to participate in a pilot study and modified ambiguous items based on some problems observed. We conducted an exploratory factor analysis to test the constructs. The results showed that the value of Kaiser-Meyer-Olkin (KMO) was 0.912 and Bartlett's test of sphericity was significant. Finally, 46 items were included in the questionnaire.

The questionnaire consisted of three sections. First, the aim of this study was described, the conditions for participants to participate in the survey anonymously were described, and examples (Chunyuyisheng and Haodaifuzaixian) clarifying mHealth apps were provided. In addition, it was explained in the first part that only users who have previously used mHealth apps can participate in the survey. The second section is used for demographic issues, including age, gender, education level, and occupation. The last section is used to measure the 11 constructs in the research model.

\subsection{Data Collection}

We collected data through an online survey. All participants were required to have used mHealth apps. First, before issuing the questionnaire, we ensured that the participants had understood and used mHealth apps. Second, the questionnaire was online distributed through a Chinese online platform (Sojump). Sojump is the largest online survey platform in China, with 35.36 million users. Participants have reached Sojump and downloaded 
the questionnaire at the time of the researchers' study. They have validly answered the researchers' questions and voluntarily have no compensation or gifts to avoid potential biases. From March 2020 to June 2020, we completed the online survey by 380 smartphone users who have used mHealth apps. We excluded incomplete questionnaires and obtained 327 valid responses with a response rate of $86 \%$.

We calculated the demographic characteristics, which are listed in Table 1. Of all respondents, $51.1 \%$ were females, while males accounted for $48.9 \%$ of all participants; $47.7 \%$ of participants were aged between 18 and 29 years, $40.1 \%$ of participants belonged to the $30-40$ age group, and $12.2 \%$ were aged 40 years and above. Most participants (83.5\%) in this study were college graduates. The majority of the participants' experiences on mHealth apps usage were within 1 year $(72.5 \%)$.

Table 1. Demographic profiles of samples $(\mathrm{N}=327)$.

\begin{tabular}{|c|c|c|}
\hline Demographic Profile & Frequency & Percentage $(\%)$ \\
\hline \multicolumn{3}{|l|}{ Gender } \\
\hline Male & 160 & 48.9 \\
\hline Female & 167 & 51.1 \\
\hline \multicolumn{3}{|l|}{ Age } \\
\hline $18-29$ & 156 & 47.7 \\
\hline $30-39$ & 131 & 40.1 \\
\hline 40 and above & 40 & 12.2 \\
\hline \multicolumn{3}{|l|}{ Level of education } \\
\hline High school and below & 20 & 6.1 \\
\hline College graduate & 273 & 83.5 \\
\hline Postgraduate and above & 34 & 10.4 \\
\hline \multicolumn{3}{|c|}{ Experience in using mHealth apps } \\
\hline 1 years and below & 237 & 72.5 \\
\hline $1-3$ years & 76 & 23.2 \\
\hline 3 years and above & 14 & 4.3 \\
\hline
\end{tabular}

\subsection{Data Analysis}

To test the proposed hypotheses, this study conducted a three-step analysis method. First, this study used SPSS Statistics 25 to test the measurement model through confirmatory factor analysis. Second, this study used AMOS 26 to test the structural model through the structural equation model approach [72]. Third, this study used the bootstrapping analysis method to test the mediating role of e-satisfaction and the hierarchical regression method to test the moderating effect of habit [73].

\section{Results}

\subsection{Measurement Model Analysis}

The measurement model comes from the structural equation model and consists of the measurement instruments and constructs. The means and standard deviations of all constructs are listed in Table 2. We examine the reliability, content validity, and structural validity of each construct based on the sample examination. We conduct a confirmatory factor analysis. Since all the scales are based on existing studies, the validity of the questionnaire content is ensured. Cronbach's alpha and composite reliability both exceed 0.7, which supports the reliability of the questionnaire [74]. Moreover, all factor loadings over 0.7 and the results reflect the good convergent validity of our scales [74]. All constructs' average variance extracted (AVE) exceeded the acceptable value. 
Table 2. Results of Constructs Validity and Reliability.

\begin{tabular}{|c|c|c|c|c|c|c|c|}
\hline Construct & Item & Mean & $\mathrm{SD}^{12}$ & Factor Loading & Cronbach's Alpha & $\mathrm{CR}^{13}$ & $\operatorname{AVE}^{14}$ \\
\hline \multirow{4}{*}{$\mathrm{PE}^{1}$} & PE1 & 5.917 & 0.834 & 0.761 & \multirow{4}{*}{0.750} & \multirow{4}{*}{0.839} & \multirow{4}{*}{0.567} \\
\hline & PE2 & 5.404 & 1.128 & 0.699 & & & \\
\hline & PE3 & 5.700 & 1.103 & 0.735 & & & \\
\hline & PE4 & 5.572 & 1.352 & 0.813 & & & \\
\hline \multirow{4}{*}{$\mathrm{EE}^{2}$} & EE1 & 5.823 & 1.131 & 0.742 & \multirow{4}{*}{0.760} & \multirow{4}{*}{0.831} & \multirow{4}{*}{0.552} \\
\hline & EE2 & 5.147 & 1.532 & 0.814 & & & \\
\hline & EE3 & 5.697 & 1.336 & 0.692 & & & \\
\hline & EE4 & 5.648 & 1.115 & 0.719 & & & \\
\hline \multirow{4}{*}{$\mathrm{SI}^{3}$} & SI1 & 5.208 & 1.571 & 0.798 & \multirow{4}{*}{0.800} & \multirow{4}{*}{0.868} & \multirow{4}{*}{0.622} \\
\hline & SI2 & 5.067 & 1.506 & 0.766 & & & \\
\hline & SI3 & 5.128 & 1.598 & 0.770 & & & \\
\hline & SI4 & 5.313 & 1.420 & 0.819 & & & \\
\hline \multirow{4}{*}{$\mathrm{FC}^{4}$} & FC1 & 5.624 & 1.745 & 0.690 & \multirow{4}{*}{0.744} & \multirow{4}{*}{0.837} & \multirow{4}{*}{0.563} \\
\hline & FC2 & 5.547 & 1.440 & 0.752 & & & \\
\hline & FC3 & 5.297 & 1.218 & 0.820 & & & \\
\hline & FC4 & 5.425 & 1.302 & 0.733 & & & \\
\hline \multirow{4}{*}{$\mathrm{PR}^{5}$} & PR1 & 5.517 & 1.149 & 0.703 & \multirow{4}{*}{0.767} & \multirow{4}{*}{0.860} & \multirow{4}{*}{0.607} \\
\hline & PR2 & 5.005 & 1.298 & 0.776 & & & \\
\hline & PR3 & 5.244 & 1.101 & 0.853 & & & \\
\hline & PR4 & 5.560 & 0.999 & 0.777 & & & \\
\hline \multirow{3}{*}{$\mathrm{PV}^{6}$} & PV1 & 5.358 & 1.233 & 0.765 & \multirow{3}{*}{0.780} & \multirow{3}{*}{0.841} & \\
\hline & PV2 & 5.413 & 1.135 & 0.759 & & & 0.799 \\
\hline & PV3 & 5.495 & 1.198 & 0.869 & & & \\
\hline & ORE1 & 5.323 & 1.210 & 0.761 & & & \\
\hline & ORE2 & 5.294 & 1.174 & 0.730 & & & \\
\hline & ORE3 & 4.917 & 1.617 & 0.716 & & & \\
\hline ORE $^{7}$ & ORE4 & 5.321 & 1.331 & 0.801 & 0.852 & 0.912 & 0.597 \\
\hline & ORE5 & 5.165 & 1.367 & 0.745 & & & \\
\hline & ORE6 & 5.171 & 1.512 & 0.862 & & & \\
\hline & ORE7 & 5.596 & 1.250 & 0.786 & & & \\
\hline & ESA1 & 5.670 & 0.992 & 0.722 & & & \\
\hline & ESA2 & 5.294 & 1.296 & 0.746 & & & \\
\hline ESA $^{8}$ & ESA3 & 5.498 & 1.125 & 0.846 & 0.784 & 0.852 & 0.590 \\
\hline & ESA4 & 5.495 & 1.247 & 0.753 & & & \\
\hline & CUI1 & 5.853 & 1.011 & 0.745 & & & \\
\hline $\mathrm{CUI}^{9}$ & CUI2 & 5.765 & 1.214 & 0.758 & 0.809 & 0.789 & 0.556 \\
\hline & CUI3 & 5.627 & 1.378 & 0.733 & & & \\
\hline & CUB1 & 5.428 & 1.381 & 0.718 & & & \\
\hline $\mathrm{CUB}^{10}$ & CUB2 & 5.356 & 1.482 & 0.752 & 0.724 & 0.775 & 0.535 \\
\hline & CUB3 & 5.480 & 1.244 & 0.723 & & & \\
\hline & HAB1 & 5.064 & 1.724 & 0.820 & & & \\
\hline & HAB2 & 4.957 & 1.265 & 0.751 & & & \\
\hline $\mathrm{HAB}^{11}$ & HAB3 & 5.076 & 1.352 & 0.788 & 0.853 & 0.871 & 0.629 \\
\hline & HAB4 & 4.971 & 1.686 & 0.811 & & & \\
\hline
\end{tabular}

${ }^{1}$ Performance Expectancy, ${ }^{2}$ Effort Expectancy, ${ }^{3}$ Social Influence, ${ }^{4}$ Facilitating Conditions, ${ }^{5}$ Perceived Reliability, ${ }^{6}$ Price Value, ${ }^{7}$ Online Review, ${ }^{8}$ E-satisfaction, ${ }^{9}$ Continued Usage Intention, ${ }^{10}$ Continued Usage Behavior

${ }^{11}$ Habit, ${ }^{12}$ Standard Deviation, ${ }^{13}$ Composite Reliability, ${ }^{14}$ Average Variance Extraction.

Discriminant validity is the degree to which measurement instruments are uncorrelated with other different constructs. Discriminant validity is exhibited if constructs' square roots of AVE are greater than the correlation coefficient of the construct with any other construct [75]. Table 3 shows the good discriminant validity of the constructs. To test the model fit of the research model, we measure the fit indices and the results are as shown in Table 4 that indicates the goodness of fit assessments for the research model. In 
addition, this study used self-reported data, which may cause common method bias [76]. To investigate common method bias, this study conducts Harmon's one-factor test and found that the single factor could explain $37 \%$ of the total variance. Thus, this study does not have a common method bias.

Table 3. Discriminant Validity.

\begin{tabular}{|c|c|c|c|c|c|c|c|c|c|c|c|}
\hline & PE & EE & SI & FC & PR & PV & ORE & ESA & CUI & CUB & НАВ \\
\hline $\mathrm{PE}^{1}$ & $0.757^{12}$ & & & & & & & & & & \\
\hline $\mathrm{EE}^{2}$ & $0.528^{13}$ & 0.743 & & & & & & & & & \\
\hline $\mathrm{SI}^{3}$ & 0.677 & 0.676 & 0.789 & & & & & & & & \\
\hline $\mathrm{FC}^{4}$ & 0.561 & 0.461 & 0.514 & 0.750 & & & & & & & \\
\hline $\mathrm{PR}^{5}$ & 0.441 & 0.253 & 0.261 & 0.409 & 0.779 & & & & & & \\
\hline $\mathrm{PV}^{6}$ & 0.673 & 0.581 & 0.681 & 0.391 & 0.303 & 0.799 & & & & & \\
\hline ORE $^{7}$ & 0.507 & 0.339 & 0.481 & 0.243 & 0.187 & 0.549 & 0.773 & & & & \\
\hline $\mathrm{ESA}^{8}$ & 0.685 & 0.518 & 0.626 & 0.537 & 0.335 & 0.594 & 0.494 & 0.768 & & & \\
\hline CUI $^{9}$ & 0.666 & 0.597 & 0.645 & 0.468 & 0.412 & 0.684 & 0.480 & 0.571 & 0.745 & & \\
\hline $\mathrm{CUB}^{10}$ & 0.452 & 0.358 & 0.505 & 0.225 & 0.216 & 0.626 & 0.451 & 0.440 & 0.536 & 0.731 & \\
\hline НAB 11 & 0.005 & 0.024 & 0.087 & 0.066 & 0.066 & 0.195 & 0.123 & 0.006 & 0.033 & 0.059 & 0.793 \\
\hline
\end{tabular}

${ }^{1}$ Performance Expectancy, ${ }^{2}$ Effort Expectancy, ${ }^{3}$ Social Influence, ${ }^{4}$ Facilitating Conditions, ${ }^{5}$ Perceived Reliability, ${ }^{6}$ Price Value, ${ }^{7}$ Online Review, ${ }^{8}$ E-satisfaction, ${ }^{9}$ Continued Usage Intention, ${ }^{10}$ Continued Usage Behavior,

${ }^{11}$ Habit, ${ }^{12}$ Diagonal values are squared roots of AVE, ${ }^{13}$ Off-diagonal values are the estimates of inter-correlation between the latent constructs.

Table 4. Goodness of fit assessments for the research model.

\begin{tabular}{cccccc}
\hline Goodness of Fit Measures & CMIN/DF $^{\mathbf{1}}$ & IFI $^{2}$ & TLI $^{3}$ & CFI $^{4}$ & RMSEA $^{\mathbf{5}}$ \\
\hline Goodness of fit ranges & $1-3$ & $>0.900$ & $>0.900$ & $>0.900$ & $<0.050$ \\
Model fit & 1.135 & 0.985 & 0.981 & 0.985 & 0.020
\end{tabular}

${ }^{1}$ Chi square/Degrees of freedom, ${ }^{2}$ Incremental fit index, ${ }^{3}$ Tucker-Lewis index, ${ }^{4}$ Comparative fit index

${ }^{5}$ Root-mean-square error of approximation.

\subsection{Structural Model Analysis}

The results of the hypothesis testing, including standardized path coefficients, and the amount of variance explained are shown in Table 5 and Figure 2. The results show that our hypotheses were supported. The relationship between performance expectancy and continued usage intention was found to be statistically significant, thereby supporting H1. The results reveal the significant impact of effort expectancy, social influence, facilitating conditions, perceived reliability, price value, online review on users' continued intention of using mHealth apps. Thus, this study identified the effects of antecedents on continued usage intention, and $\mathrm{H} 2, \mathrm{H} 3, \mathrm{H} 4, \mathrm{H} 5, \mathrm{H} 6$, and $\mathrm{H} 7$ were supported. Moreover, this study found that e-satisfaction positively affects continued usage intention and H8 was supported. Consistent with existing studies [12], this study also verified the positive relationship between behavioral intention and usage behavior. In addition, as displayed on Table 5, we found a moderation effect of habit on the relationship between continued usage intention and users' e-satisfaction with mHealth apps. Thus, H11 was supported.

This study examined the mediating model using 5000 bootstrap samples, which has been proven to be more accurate than the Sobel test $[73,77]$. As shown in Table 6, all indirect effects are significant and the $95 \%$ confidence interval for the estimates of the mediation effects excludes 0 [27]. Thus, the bootstrapping results showed that the mediation effects of e-satisfaction were significant. In addition, we used the hierarchical regression method to test the moderation effect. As shown in Table 5 and Figure 3, the higher habit will strengthen the positive relationship between user e-satisfaction and continued usage intention. 
Table 5. Results of the Hypotheses Testing.

\begin{tabular}{cccccc}
\hline Hypothesis & Relationship & Std. Beta & Std. Error & $t$-Value & Result \\
\hline H1 & $\mathrm{PE}^{1} \rightarrow$ ESA & $0.431^{* * * 12}$ & 0.063 & 7.254 & Support \\
H2 & $\mathrm{EE}^{2} \rightarrow$ ESA & $0.335^{* * *}$ & 0.047 & 7.128 & Support \\
H3 & SI $^{3} \rightarrow$ ESA & $0.273^{* * *}$ & 0.051 & 5.352 & Support \\
H4 & $\mathrm{FC}^{4} \rightarrow$ ESA & $0.126^{* *} 13$ & 0.036 & 3.315 & Support \\
H5 & $\mathrm{PR}^{5} \rightarrow$ ESA & $0.215^{* *}$ & 0.068 & 4.357 & Support \\
H6 & $\mathrm{PV}^{6} \rightarrow$ ESA & $0.526^{* * *}$ & 0.071 & 7.408 & Support \\
H7 & $\mathrm{ORE}^{7} \rightarrow$ ESA & $0.371^{* * *}$ & 0.055 & 6.745 & Support \\
H8 & $\mathrm{ESA}^{8} \rightarrow$ CUI & $0.763^{* * *}$ & 0.092 & 8.293 & Support \\
H9 & $\mathrm{CUI}^{9} \rightarrow$ CUB & $0.812^{* * *}$ & 0.101 & 8.039 & Support \\
H10 & $\mathrm{HAB}^{11} \rightarrow$ CUB & $0.216^{* * *}$ & 0.039 & 5.538 & Support \\
H11 & $\mathrm{HAB} \mathrm{and} \mathrm{ESA} \rightarrow$ CUI & $0.317^{* * *}$ & 0.056 & 5.661 & Support \\
\hline
\end{tabular}

${ }^{1}$ Performance Expectancy, ${ }^{2}$ Effort Expectancy, ${ }^{3}$ Social Influence, ${ }^{4}$ Facilitating Conditions, ${ }^{5}$ Perceived Reliability

${ }^{6}$ Price Value, ${ }^{7}$ Online Review, ${ }^{8}$ E-satisfaction, ${ }^{9}$ Continued Usage Intention, ${ }^{10}$ Continued Usage Behavior,

${ }^{11}$ Habit, $12 * * * p<0.001,13 * * p<0.01$.

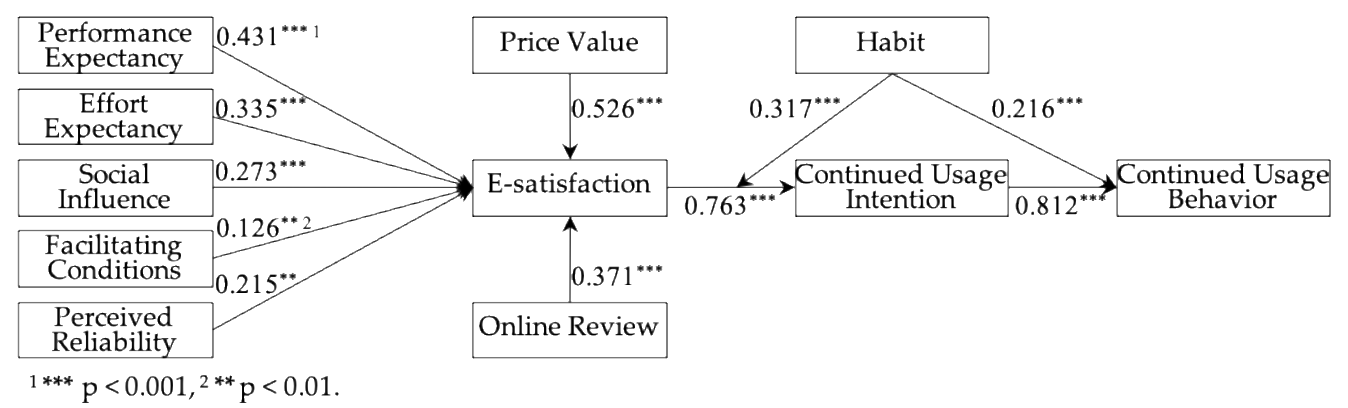

Figure 2. Results of the hypotheses testing.

Table 6. Bootstrapping analysis of the mediation effect of e-satisfaction.

\begin{tabular}{|c|c|c|c|c|c|c|}
\hline \multirow{2}{*}{ Effects } & \multirow{2}{*}{$\begin{array}{c}\text { Dependent } \\
\text { Variable }\end{array}$} & \multirow{2}{*}{ CUI ${ }^{8}$} & \multirow{2}{*}{ Effects } & \multirow{2}{*}{ Boot SE } & \multicolumn{2}{|c|}{ Bootstrap 95\% CI } \\
\hline & & & & & Boot LLCI & Boot ULCI \\
\hline \multirow{7}{*}{ Total Effects } & \multirow{7}{*}{$\begin{array}{c}\text { Independent } \\
\text { Variables }\end{array}$} & $\mathrm{PE}^{1}$ & $0.532 * * * 9$ & 0.080 & 0.378 & 0.686 \\
\hline & & $\mathrm{EE}^{2}$ & $0.494^{* * *}$ & 0.047 & 0.405 & 0.588 \\
\hline & & $\mathrm{SI}^{3}$ & $0.345^{* * *}$ & 0.045 & 0.256 & 0.433 \\
\hline & & $\mathrm{FC}^{4}$ & $0.465^{* * *}$ & 0.045 & 0.383 & 0.556 \\
\hline & & $\mathrm{PR}^{5}$ & $0.473^{* * *}$ & 0.043 & 0.391 & 0.560 \\
\hline & & $\mathrm{PV}^{6}$ & $0.686^{* * *}$ & 0.057 & 0.577 & 0.802 \\
\hline & & ORE $^{7}$ & $0.308^{* * *}$ & 0.024 & 0.261 & 0.355 \\
\hline \multirow{7}{*}{$\begin{array}{l}\text { Indirect } \\
\text { Effects }\end{array}$} & \multirow{7}{*}{$\begin{array}{c}\text { Independent } \\
\text { Variables }\end{array}$} & PE & $0.215^{* * *}$ & 0.043 & 0.081 & 0.370 \\
\hline & & $\mathrm{EE}$ & $0.229^{* * *}$ & 0.037 & 0.133 & 0.322 \\
\hline & & SI & $0.095 * 10$ & 0.033 & 0.032 & 0.160 \\
\hline & & FC & $0.189^{* * *}$ & 0.037 & 0.105 & 0.279 \\
\hline & & PR & $0.191 * * *$ & 0.038 & 0.113 & 0.271 \\
\hline & & PV & $0.346^{* * *}$ & 0.051 & 0.222 & 0.473 \\
\hline & & ORE & $0.134^{* * *}$ & 0.027 & 0.081 & 0.187 \\
\hline \multirow{7}{*}{ Direct Effects } & \multirow{7}{*}{$\begin{array}{c}\text { Independent } \\
\text { Variables }\end{array}$} & PE & $0.683^{* * *}$ & 0.045 & 0.532 & 0.849 \\
\hline & & $\mathrm{EE}$ & $0.589^{* * *}$ & 0.043 & 0.490 & 0.697 \\
\hline & & SI & $0.473^{* * *}$ & 0.051 & 0.372 & 0.574 \\
\hline & & FC & $0.581^{* * *}$ & 0.043 & 0.489 & 0.669 \\
\hline & & PR & $0.605^{* * *}$ & 0.041 & 0.513 & 0.699 \\
\hline & & PV & $0.850^{* * *}$ & 0.050 & 0.741 & 0.959 \\
\hline & & ORE & $0.410^{* * *}$ & 0.024 & 0.363 & 0.457 \\
\hline
\end{tabular}

${ }^{1}$ Performance Expectancy, ${ }^{2}$ Effort Expectancy, ${ }^{3}$ Social Influence, ${ }^{4}$ Facilitating Conditions, ${ }^{5}$ Perceived Reliability, ${ }^{6}$ Price Value, ${ }^{7}$ Online Review, ${ }^{8}$ Continued Usage Intention, ${ }^{9 * * *} p<0.001,10 * * p<0.01$. 


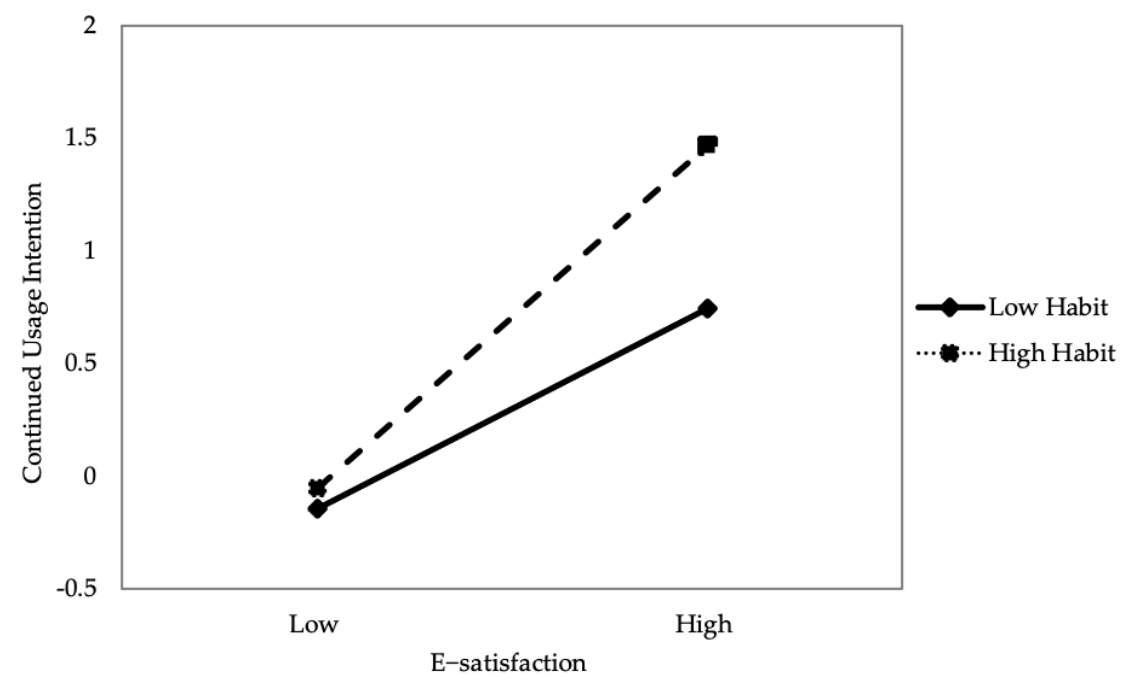

Figure 3. Results of the moderation effect.

\section{Discussion}

This study aims to explore the influences of users' continued behaviors of mHealth apps usage from the perspective of UTAUT2. Our results proved that performance expectancy, social influence, facilitating conditions, perceived reliability, price value, online review have significant positive impacts on users' continued usage intention through the mediation role of e-satisfaction. Moreover, users' continued intention positively impacts the usage behavior of keeping to use mHealth apps. It is further identified that habits of using mHealth apps enhance the positive effect of e-satisfaction on continued usage intention.

This study identifies that habit directly affects users' continuous use of mHealth apps and users should be attracted to form the habit of mHealth apps usage, which is crucial to these apps' successful development. Interestingly, the stronger the habit of using mHealth apps, the stronger the relationship between users' e-satisfaction and their willingness to continue using mHealth apps. Generally, individuals who are satisfied with experience tend to repeat the behavior. Furthermore, individuals who develop habits towards emerging technologies are likely to continue to use the apps.

Two constructs (perceived reliability and online review) added to the research model have important effects on the continued intention of using mHealth apps. For example, users are significantly interested in the availability of online comments provided by others in mHealth apps. This suggests that users regard such comments as reliable, useful, and relevant health sources in these platforms when consulting professional physicians. Thus, extant reviews published by others can be easily accessed and conveniently through mHealth apps. In addition, continued behavior of mHealth apps usage also can facilitate users' seeking health information, thereby saving their time and effort. In this study, the empirical results show that all hypotheses have been verified and the extended UTAUT2 is an important theoretical model for predicting the continued use of mHealth apps.

\subsection{Theoretical Implications}

Because mHealth apps are an emerging technology in China, a deeper understanding of the usage of these apps is required. Our purpose is to explore the effects of users' e-satisfaction with mHealth apps and actual usage behavior from the perspective of the extended UTAUT2. There are some theoretical implications in the study.

First, this study pays attention to users' continued acceptance of mHealth apps. Prior studies mainly examined the effect of users' initial behavioral intention of emerging technologies while ignoring continuous usage behaviors. However, uses' continuous intention and usage behavior are significantly important for the success of emerging technologies. This study extends the UTAUT2 in the field of continuous use of mHealth apps. 
Second, this study contributes by validating the effects of perceived reliability and online review on e-satisfaction with mHealth apps. In the context of healthcare services, due to the life-threatening possibilities, perceived reliability is important for their selection. In the context of mobile apps, people believe that online reviews are valuable sources of information when they are selecting services and products. Thus, in these two respects, this study integrates perceived reliability and online reviews into the UTAUT2 model, which enriches the theoretical framework.

Third, the key strength of this study is revealing the moderating role of habits. The results reveal that when people are accustomed to using mobile apps, then the relationship between e-satisfaction and continued intention will be enhanced. Habit has the moderating effect between e-satisfaction and continued intention of using mHealth apps, and this finding enriches the research on mHealth apps and expands the theoretical scope of UTAUT2.

\subsection{Practical Implications}

The study has some practical implications regarding the understanding of designing and managing mHealth apps. First, managers of mHealth apps should organize promotional activities and pay attention to the roles of performance expectation and effort expectation. Users of mHealth apps should be encouraged to use mHealth apps due to requiring less time and effort compared to the traditional ways of waiting and visiting hospitals. In addition, the price value of health services on mHealth apps positively affects continued usage intention through the mediation role of e-satisfaction. In this study, we suggest that managers should regulate the price value of health services on mHealth apps.

Second, managers should encourage users to publish rich online reviews on the features and health services of mHealth apps. For example, the number of users who review their attitude of the experience in such apps should be a focus. To ensure that online review is relevant and credible to other users, mHealth apps should improve the information quality of the published online reviews [53], which convinces users that online reviews are valuable to acquire health services and information. In addition, this study found that users' habits moderated the positive relationship between e-satisfaction and continued intention of using mHealth apps. Users' habits can be enhanced by personalized notifications of using mHealth apps [78].

Third, managers of mHealth apps could focus on increasing users' e-satisfaction with the functions of mobile platforms, thereby improving users' intention of continues using mHealth apps to seek health information and services. In addition, if users receive highquality and friendly personalized healthcare services, then they will be satisfied with their experience and the high value of using such apps. Regarding mHealth apps that have the ability to capture and record large amounts of patient data, physicians could implement and provide personalized health services through these mobile platforms. Moreover, users have autonomous control in the processes of consulting and can provide appropriate and relevant solutions to problems in mHealth apps.

\subsection{Limitations and Future Research Directions}

Though this study is dedicated to providing insights into using mHealth apps, there are also some noted limitations. First, due to the nature of cross-sectional research, this study could not accurately explain users' perceptions of mHealth apps within the time frame. Future studies should conduct longitudinal research to discuss users' perceptions and attitudes toward mHealth apps over time. Second, in the current study, to draw conclusions from this special subgroup for the entire Chinese group of 18-70-year-olds who use the mHealth apps is a limitation. In future research, other types of sampling techniques for collecting data should be considered to apply. Third, though amounts of constructs have been considered in the current study, other constructs, such as health service quality, doctor-patient interaction, and individuation, should be studied. In addition, personality trait constructs, such as self-efficacy, e-health literacy, and health consciousness, should be considered, as this might shed light on the insights of supporting mHealth apps usage. 


\section{Conclusions}

Considering the particularities of mHealth apps, we propose a research model based on the appropriate theoretical model that extends two factors, perceived reliability and online review, to the original UTAUT2 to explore the effects of factors on the continued behavior of using mHealth apps. Our results prove that performance expectancy, social influence, facilitating conditions, perceived reliability, price value, online review have significant positive impacts on users' continued usage intention through the mediation role of e-satisfaction. Moreover, users' continued intention positively impacts the usage behavior of keeping to use mHealth apps. It is further identified that habits of using mHealth apps enhance the positive effect of e-satisfaction on continued usage intention. Finally, we express theoretical and practical implications and discuss the limitations and future research directions.

Author Contributions: All authors contributed to this study. P.W. participated in designing the study and developing the research model, designed the questionnaire, conducted data collection and analysis, and is a major contributor in writing and revising the manuscript. R.Z. conceived and designed the study, developed the research model, and modified the manuscript. X.Z. and M.L. helped modify the manuscript. All authors have read and agreed to the published version of the manuscript.

Funding: This research was supported by National Social Science Foundation of China (major program, grant number 18ZDA086); National Natural Science Foundation of China (grant number 62173025); Fundamental Research Funds of the Central University (grant number 2020YJS069). The authors appreciate the support of the Beijing Logistics Informatics Research Base.

Data Availability Statement: The data presented in this study are available on request from the corresponding author.

Conflicts of Interest: The authors declare no conflict of interest.

\section{Appendix A. Measurement Items}

Table A1. Measurement items of constructs.

\begin{tabular}{|c|c|c|c|}
\hline Constructs & Items & Statements & Sources \\
\hline Performance Expectancy (PE) & $\begin{array}{l}\text { PE1 } \\
\text { PE2 } \\
\text { PE3 } \\
\text { PE4 }\end{array}$ & $\begin{array}{l}\text { I think mHealth apps is helpful for my health. } \\
\text { I think mHealth apps could solve individual health problems. } \\
\text { I think mHealth apps can manage individual health quickly. } \\
\text { I think mHealth apps can increase the capability of health self-management. }\end{array}$ & {$[28,33]$} \\
\hline Effort Expectancy (EE) & $\begin{array}{l}\text { EE1 } \\
\text { EE2 } \\
\text { EE3 } \\
\text { EE4 }\end{array}$ & $\begin{array}{l}\text { I think I can easily learn to use mHealth apps. } \\
\text { I can understand the health information on mHealth apps. } \\
\text { I can easily use mHealth apps. } \\
\text { I can get the skill of using mHealth apps. }\end{array}$ & {$[28,33]$} \\
\hline Social Influence (SI) & $\begin{array}{l}\text { SI1 } \\
\text { SI2 } \\
\text { SI3 } \\
\text { SI4 }\end{array}$ & $\begin{array}{l}\text { I would adopt mHealth apps based on friends' and relatives' perspectives. } \\
\text { I would adopt mHealth apps based on individuals who influence my behavior. } \\
\text { I would adopt mHealth apps based on friends and relatives. } \\
\text { Using mHealth apps is more prestigious than not using them. }\end{array}$ & {$[28,33]$} \\
\hline Facilitating Conditions (FC) & $\begin{array}{l}\text { FC1 } \\
\text { FC2 } \\
\text { FC3 } \\
\text { FC4 }\end{array}$ & $\begin{array}{l}\text { I possess the resources needed to accept mHealth apps. } \\
\text { I possess the knowledge needed to accept mHealth apps. } \\
\text { The adoption of technologies is consistent with my others. } \\
\text { I can acquire helps from others when I account for problems. }\end{array}$ & {$[28,33]$} \\
\hline Perceived Reliability (PR) & $\begin{array}{l}\text { PR1 } \\
\text { PR2 } \\
\text { PR3 } \\
\text { PR4 }\end{array}$ & $\begin{array}{l}\text { I can get exact and true health information in mHealth apps. } \\
\text { I depend on the health information through mHealth apps. } \\
\text { I think mHealth apps are persistent. } \\
\text { I think mHealth apps keep criterion constantly. }\end{array}$ & [12] \\
\hline Price Value (PV) & $\begin{array}{l}\text { PV1 } \\
\text { PV2 } \\
\text { PV3 }\end{array}$ & $\begin{array}{l}\text { I can get knowledge at a rational price through these apps. } \\
\text { Health services in mHealth apps are fine price for money. } \\
\text { mHealth apps offer worth for users in price. }\end{array}$ & {$[13,33]$} \\
\hline
\end{tabular}


Table A1. Cont.

\begin{tabular}{clc}
\hline Constructs & Items & Statements \\
\hline & ORE1 & Online reviews in mHealth apps are believable. \\
& ORE2 & Online reviews in mHealth apps are relevant to my demands. \\
Online Review (ORE) & ORE3 & Online reviews in mHealth apps are trusted. \\
& ORE4 & Online reviews in mHealth apps have adequate deepness. \\
& ORE5 & Online reviews in mHealth apps have adequate broadness. \\
& ORE6 & Online reviews' quantities can satisfy my health demands. \\
& ORE7 & Online reviews are useful to assess health information.
\end{tabular}

\section{References}

1. Wallis, L.; Blessing, P.; Dalwai, M.; Shin, S.D. Integrating mHealth at point of care in low-and middle-income settings: The system perspective. Glob. Health Action 2017, 10, 1327686. [CrossRef]

2. Sadegh, S.S.; Khakshour, P.S.; Sepehri, M.M.; Assadi, V. A framework for m-health service development and success evaluation. Int. J. Med. Inform. 2018, 112, 123-130. [CrossRef]

3. Zhang, X.; Yan, X.; Cao, X.; Sun, Y.; Chen, H.; She, J. The role of perceived e-health literacy in users' continuance intention to use mobile healthcare applications: An exploratory empirical study in China. Inf. Technol. Dev. 2018, 24, 198-223. [CrossRef]

4. Pyrogen Testing Market. Zion Market Research, New York, NY, USA. Available online: https:/ /www.zionmarketresearch.com/ report/mhealth-apps-market (accessed on 23 January 2019).

5. Nisha, N.; Iqbal, M.; Rifat, A. The changing paradigm of health and mobile phones: An innovation in the health care system. J. Glob. Inf. Manag. 2019, 27, 19-46. [CrossRef]

6. Cho, J. The impact of post-adoption beliefs on the continued use of health apps. Inter. J. Med. Inform. 2015, 87, 75-83. [CrossRef] [PubMed]

7. Kim, E.; Han, S. Determinants of continuance intention to use health apps among users over 60: A test of social cognitive model. Int. J. Environ. Res. Public Health 2021, 18, 10367. [CrossRef]

8. Lee, E.; Han, S.; Jo, S.H. Consumer choice of on-demand mHealth app services: Context and contents values using structural equation modeling. Inter. J. Med. Inform. 2017, 97, 229-238. [CrossRef] [PubMed]

9. Chiu, W.; Cho, H.; Chi, C. Consumers' continuance intention to use fitness and health apps: An integration of the expectationconfirmation model and investment model. Inf. Technol. People 2021, 34, 978-998. [CrossRef]

10. Sun, Y.; Wang, N.; Guo, X.; Peng, Z. Understanding the acceptance of mobile health services: A comparison and integration of alternative models. J. Electron. Commer. Res. 2013, 14, 183-200.

11. Mohammad, Z.A.; Rakibul, H.; Wang, H.; Zapan, B. Factors influencing the adoption of mHealth services in a developing country: A patient-centric study. Int. J. Inf. Manag. 2020, 50, 128-143.

12. Zhang, X.; Han, X.; Dang, Y.; Meng, F.; Guo, X.; Lin, J. User acceptance of mobile health services from users' perspectives: The role of self-efficacy and response-efficacy in technology acceptance. Inform. Health Soc. Care 2017, 42, 194-206. [CrossRef] [PubMed]

13. Alalwan, A.A. Mobile food ordering apps: An empirical study of the factors affecting customer e-satisfaction and continued intention to reuse. Int. J. Inf. Manag. 2020, 50, 28-44. [CrossRef]

14. Zhu, K.; Liu, Z.; Zhang, L.; Gu, X. A mobile application recommendation framework by exploiting personal preference with constraints. Mob. Inf. Syst. 2017, 2017, 9. [CrossRef]

15. Soodan, V.; Rana, A. Modeling customers' intention to use e-wallet in a developing nation: Extending UTAUT2 with security, privacy and savings. J. Electron. Commer. Organ. 2020, 18, 89-114. [CrossRef] 
16. Krebs, P.; Duncan, D.T. Health app use among US mobile phone owners: A national survey. JMIR mHealth $u$ Health 2015, 3 , 107-119. [CrossRef]

17. Radzi, C.; Jenatabadi, H.S.; Samsudin, N. mHealth Apps Assessment among Postpartum Women with Obesity and Depression Healthcare 2020, 8, 72. [CrossRef]

18. Hoque, M.R. An empirical study of mHealth adoption in a developing country: The moderating effect of gender concern. BMC Med. Inform. Decis. Mak. 2016, 16, 51. [CrossRef]

19. Khatun, F.; Heywood, A.E.; Ray, P.K.; Bhuiya, A.; Liaw, S.T. Community readiness for adopting mHealth in rural Bangladesh: A qualitative exploration. Int. J. Med. Inform. 2016, 93, 49-56. [CrossRef]

20. Murnane, E.L.; Huffaker, D.; Kossinets, G. Mobile Health Apps: Adoption, Adherence, and Abandonment. In Proceedings of the 2015 ACM International Joint Conference on Pervasive and Ubiquitous Computing and the 2015 ACM International Symposium on Wearable Computers, Osaka, Japan, 7-11 September 2015.

21. Tajudeen, F.P.; Bahar, N.; Maw Pin, T.; Saedon, N.I. Mobile technologies and healthy ageing: A bibliometric analysis on publication trends and knowledge structure of mHealth research for older adults. Int. J. Hum.-Compt. Interact. 2022, 38, 118-130. [CrossRef]

22. Whitehead, L.; Seaton, P. The effectiveness of self-management mobile phone and tablet apps in long-term condition management: A systematic review. J. Med. Internet. Res. 2016, 18, 12. [CrossRef]

23. Wang, C.; Qi, H.Y. Influencing factors of acceptance and use behavior of mobile health application users: Systematic review. Healthcare 2021, 9, 357. [CrossRef]

24. Mao, X.; Zhao, X.; Liu, Y. mHealth App recommendation based on the prediction of suitable behavior change techniques. Decis. Support. Syst. 2020, 132, 113248. [CrossRef]

25. Hoque, R.; Sorwar, G. Understanding factors influencing the adoption of mHealth by the elderly: An extension of the UTAUT model. Int. J. Med. Inform. 2017, 101, 75-84. [CrossRef] [PubMed]

26. Yan, M.; Filieri, R.; Raguseo, E.; Gorton, M. Mobile apps for healthy living: Factors influencing continuance intention for health apps. Technol. Forecast. Soc. Chang. 2021, 166, 120644. [CrossRef]

27. Luo, Y.; Wang, G.; Li, Y.; Ye, Q. Examining protection motivation and network externality perspective regarding the continued intention to use m-health apps. Int. J. Environ. Res. Public Health 2021, 18, 5684. [CrossRef] [PubMed]

28. Venkatesh, V.; Morris, M.G.; Davis, G.B.; Davis, F.D. User acceptance of information technology: Toward a unified view. MIS Q. 2003, 27, 425-478. [CrossRef]

29. Khan, I.U.; Yu, Y.; Hameed, Z.; Khan, S.U.; Waheed, A. Assessing the physicians' acceptance of e-prescribing in a developing country: An extension of the UTAUT model with moderating effect of perceived organizational support. J. Glob. Inf. Manag. 2018, 26, 121-142. [CrossRef]

30. De Veer, A.J.E.; Peeters, J.M.; Brabers, A.E.M.; Schellevis, F.G.; Rademakers, J.; Francke, A.L. Determinants of the intention to use e-health by community dwelling older people. BMC Health Serv. Res. 2015, 15, 103. [CrossRef]

31. Seethamraju, R.; Diatha, K.S.; Garg, S. Intention to use a mobile-based information technology solution for tuberculosis treatment monitoring-applying a UTAUT model. Inf. Syst. Front. 2018, 20, 163-181. [CrossRef]

32. Shankar, A. Impact of mobile banking application interactivity on consumer engagement: An Experiment-based investigation. $J$. Glob. Inf. Manag. 2021, 30, 1-18. [CrossRef]

33. Venkatesh, V.; Thong, J.Y.L.; Xu, X. Consumer acceptance and use of information technology: Extending the unified theory of acceptance and use of technology. MIS Q. 2012, 36, 157-178. [CrossRef]

34. Beh, P.K.; Ganesan, Y.; Iranmanesh, M.; Foroughi, B. Using smartwatches for fitness and health monitoring: The UTAUT2 combined with threat appraisal as moderators. Behav. Inf. Technol. 2021, 40, 282-299. [CrossRef]

35. Alalwan, A.A.; Dwivedi, Y.K.; Rana, N.P. Factors influencing adoption of mobile banking by Jordanian bank customers: Extending UTAUT2 with trust. Int. J. Inf. Manag. 2017, 37, 99-110. [CrossRef]

36. Korfiatis, N.; García-Bariocanal, E.; Sánchez-Alonso, S. Evaluating content quality and helpfulness of online product reviews: The interplay of review helpfulness vs. review content. Electron. Commer. Res. Appl. 2012, 11, 205-217. [CrossRef]

37. Lee, E.J.; Lee, J.; Eastwood, D. A two-step estimation of consumer adoption of technology-based service innovations. J. Consum. Aff. 2003, 37, 256-282. [CrossRef]

38. Alalwan, A.A.; Dwivedi, Y.K.; Rana, N.P.; Williams, M.D. Consumer adoption of mobile banking in Jordan: Examining the role of usefulness, ease of use, perceived risk and self-efficacy. J. Enterp. Inf. Manag. 2016, 29, 118-139. [CrossRef]

39. Ha, S.W.; Kim, J. Designing a scalable, accessible, and effective mobile app based solution for common mental health problems. Int. J. Hum.-Compt. Interact. 2020, 36, 1354-1367. [CrossRef]

40. Alagoz, S.M.; Hekimoglu, H. A study on TAM: Analysis of customer attitudes in online food ordering system. Procedia. Soc. Behav. Sci. 2012, 62, 1138-1143. [CrossRef]

41. Amin, M.; Rezaei, S.; Abolghasemi, M. User satisfaction with mobile websites: The impact of perceived usefulness (PU), perceived ease of use (PEOU) and trust. Nankai Bus. Rev. Int. 2014, 5, 258-274. [CrossRef]

42. Kaewkitipong, L.; Chen, C.C.; Ractham, P. Using social media to enrich information systems field trip experiences: Students satisfaction and continuance intentions. Comput. Hum. Behav. 2016, 63, 256-263. [CrossRef]

43. Okumus, B.; Ali, F.; Bilgihan, A.; Ozturk, A.B. Psychological factors influencing customers' acceptance of smartphone diet apps when ordering food at restaurants. Int. J. Hosp. Manag. 2018, 72, 67-77. [CrossRef] 
44. Gallarza, M.G.; Saura, I.G. Value dimensions, perceived value, satisfaction and loyalty: An investigation of university students' travel behaviour. Tour. Manag. 2006, 27, 437-452. [CrossRef]

45. Hsiao, C.H.; Chang, J.J.; Tang, K.Y. Exploring the influential factors in continuance usage of mobile social apps: Satisfaction, habit, and customer value perspectives. Telemat. Inform. 2016, 33, 342-355. [CrossRef]

46. Boontarig, W.; Chutimaskul, W.; Chongsuphajaisiddhi, V.; Papasratorn, B. Factors Influencing the Thai Elderly Intention to Use Smartphone for e-Health Services. In Proceedings of the 2012 IEEE Symposium on Humanities, Science and Engineering Research, Kuala Lumpur, Malaysia, 24-27 June 2012.

47. Chan, F.K.; Thong, J.Y.; Venkatesh, V.; Brown, S.A.; Hu, P.J.; Tam, K.Y. Modeling citizen satisfaction with mandatory adoption of an e-government technology. J. Assoc. Inf. Syst. 2010, 11, 519-549. [CrossRef]

48. Maillet, E.; Mathieu, L.; Sicotte, C. Modeling factors explaining the acceptance, actual use and satisfaction of nurses using an electronic patient record in acute care settings: An extension of the UTAUT. Int. J. Med. Inform. 2015, 84, 36-47. [CrossRef]

49. Barua, Z.; Aimin, W.; Hongyi, X. A perceived reliability-based customer satisfaction model in self-service technology. Serv. Ind. J. 2018, 38, 446-466. [CrossRef]

50. Sagib, G.K.; Zapan, B. Bangladeshi mobile banking service quality and customer satisfaction and loyalty. Manag. Mark. 2014, 9, 331-346.

51. Meuter, M.L.; Ostrom, A.L.; Roundtree, R.I.; Bitner, M.J. Self-service technologies: Understanding customer satisfaction with technology-based service encounters. J. Mark. 2000, 64, 50-64. [CrossRef]

52. Zeng, L. Factors Influencing the Adoption of Self-Service Technologies: A Study of the Benefits and Risks of Self-Service Technologies and Trust Beliefs of Service Providers; Norwegian School of Economics: Bergen, Norway, 2016.

53. Filieri, R. What makes online reviews helpful? A diagnosticity-adoption framework to explain informational and normative influences in e-WOM. J. Bus. Res. 2015, 68, 1261-1270. [CrossRef]

54. Filieri, R.; McLeay, F. E-WOM and accommodation: An analysis of the factors that influence travelers' adoption of information from online reviews. J. Travel. Res. 2013, 53, 44-57. [CrossRef]

55. Bert, F.; Giacometti, M.; Gualano, M.R.; Siliquini, R. Smartphones and health promotion: A review of the evidence. J. Med. Syst. 2014, 38, 9995. [CrossRef] [PubMed]

56. Elwalda, A.; Lü, K.; Ali, M. Perceived derived attributes of online customer reviews. Comput. Hum. Behav. 2016, 56, 306-319. [CrossRef]

57. Anderson, R.E.; Srinivasan, S.S. E-satisfaction and e-loyalty: A contingency framework. Psychol. Mark. 2003, 20, 123-138. [CrossRef]

58. Lin, J.S.C.; Hsieh, P.L. The role of technology readiness in customers' perception and adoption of self-service technologies. Int. J. Serv. Ind. Manag. 2006, 17, 497-517. [CrossRef]

59. Wang, W.; Ou, W.; Chen, W. The impact of inertia and user satisfaction on the continuance intentions to use mobile communication applications: A mobile service quality perspective. Int. J. Inf. Manag. 2019, 44, 178-193. [CrossRef]

60. Bhattacherjee, A.; Hikmet, N. Reconceptualizing organizational support and its effect on information technology usage: Evidence from the health care sector. J. Comput. Inf. Syst. 2008, 8, 69-76.

61. Recker, J. Explaining usage of process modeling grammars: Comparing three theoretical models in the study of two grammars. Inf. Manag. 2010, 47, 316-324. [CrossRef]

62. Yu, C. Factors affecting individuals to adopt mobile banking: Empirical evidence from the UTAUT Model. J. Electron. Commer. Res. 2012, 13, 104.

63. Taylor, S.; Todd, P.A. Understanding information technology usage: A test of competing models. Inform. Syst. Res. 1995, 6 , 144-176. [CrossRef]

64. Sengupta, A.; Williams, S. Can an engagement platform persuade students to stay? Applying behavioral models for retention. Int. J. Hum.-Compt. Interact. 2021, 37, 1016-1027. [CrossRef]

65. Turner, M.; Kitchenham, B.; Brereton, P.; Charters, S.; Budgen, D. Does the technology acceptance model predict actual use? A systematic literature review. Inf. Softw. Technol. 2010, 52, 463-479. [CrossRef]

66. Kijsanayotin, B.; Pannarunothai, S.; Speedie, S.M. Factors influencing health information technology adoption in Thailand's community health centers: Applying the UTAUT model. Int. J. Med. Inform. 2009, 78, 404-416. [CrossRef]

67. Limayem, M.; Hirt, S.G.; Cheung, C.M.K. How habit limits the predictive power of intention: The case of information systems continuance. MIS Q. 2007, 31, 705-737. [CrossRef]

68. Aarts, H.; Verplanken, B.; van Knippenberg, A. Predicting behavior from actions in the past: Repeated decision making or a matter of habit? J. Appl. Soc. Psychol. 1998, 28, 1355-1374. [CrossRef]

69. Ajzen, I.; Fishbein, M. The Influence of Attitudes on Behavior. In The Handbook of Attitudes; Albarracín, D., Johnson, B.T., Zanna, M.P., Eds.; Erlbaum: Mahwah, NJ, USA, 2005; pp. 173-221.

70. Amoroso, D.; Lim, R. The mediating effects of habit on continuance intention. Int. J. Inf. Manag. 2017, 37, 693-702. [CrossRef]

71. Sun, J.; Chi, T. Key factors influencing the adoption of apparel mobile commerce: An empirical study of Chinese consumers. $J$. Text. Inst. 2018, 109, 785-797. [CrossRef]

72. Kim, S.; Ham, S.; Moon, H.; Chua, B.L.; Han, H. Experience, brand prestige, perceived value (functional, hedonic, social, and financial), and loyalty among GROCERANT customers. Int. J. Hosp. Manag. 2019, 77, 169-177. [CrossRef] 
73. Zhang, X.; Liu, S. Understanding relationship commitment and continuous knowledge sharing in online health communities: A social exchange perspective. J. Knowl. Manag. 2021. ahead-of-print. [CrossRef]

74. Hair, J.F.; Black, W.C.; Babin, B.J.; Anderson, R.E.; Tatham, R.L. Multivariate Data Analysis: International Edition, 6th ed.; Prentice Hall, Inc., Division of Simon and Schuster One Lake Street Upper Saddle River: Bergen County, NJ, USA, 2010; pp. $207-219$.

75. Fornell, C.; Larcker, D.F. Evaluating structural equation models with unobservable variables and measurement error. J. Mark. Res. 1981, 18, 39-50. [CrossRef]

76. Liang, H.; Saraf, N.; Hu, Q.; Xue, Y. Assimilation of enterprise systems: The effect of institutional pressures and the mediating role of top management. MIS Q. 2007, 31, 59-87. [CrossRef]

77. Hayes, A.F. Introduction to Mediation, Moderation, and Conditional Process Analysis: A Regression-Based Approach; Guilford Publications: New York, NY, USA, 2013.

78. Ghose, A.; Guo, X.; Li, B.; Dang, Y. Empowering patients using smart mobile health platforms: A randomized field experiment. MIS Q. 2022. preprints. [CrossRef] 